sống (giảm mặn, tăng rau/củ/quả, giảm chất béo, giảm rượu/bia, ngưng hút thuốc, tập thể dục thường xuyên) được cải thiện rõ rệt. Sự khác biêt về tỷ lệ tuân thủ các chế độ ở cả bốn thời điểm T3, T6, T12 và T18 so với T0 đều có ý nghĩa thống kê $(p<0,05)$.

- Tăng tỷ lệ đạt HA mục tiêu sau can thiệp 18 tháng (T18) lên $94,5 \%$ (nữ: $98,1 \%$ cao hơn nam: 90,0\%; nhóm BN <50 tuổi: 97,0\% cao hơn nhóm 50-59 tuổi: 96,6\% và nhóm 60-69 tuổi: 92,2\%).

\section{TÀI LIÊU THAM KHẢO}

1. Nguyễn Lân Việt (2016). Kết quả mới nhất điều tra tăng huyết áp toàn quốc năm 2015 - 2016, Hội nghị tăng huyết áp Việt Nam lần thứ 2 tại Hà Nội, ngày $14-15 / 5 / 2016$.

2. Phạm Mạnh Hùng và cs (2010). Tìm hiểu và kiểm soát tăng huyết áp, Hội Tim mạch học quốc gia Viêt Nam, Hà Nôi

3. Morisky DE et al (2008). Predictive Validity of $A$ Medication Adherence Measure in an Outpatient etting, J Clin Hypertens, 10(5): 348-354.

4. Saleem F., Hassali M A., Shafie A.A (2011). Association between Knowledge and Drug Adherence in Patients with Hypertension in Quetta, Pakistan. TJPR, 10(2): 125-132.

5. Bùi Thị Nhi, Trịnh Thị Hoàng Oanh (2016). Tỷ lệ tuân thủ điều trị tăng huyết áp tai xã Phước Lơi, huyện Bến Lức, tính Long An năm 2015, Tạp chí Y học TP. Hố Hồ Chí minh, 20(1):268-272.

6. Nguyễn Thị Thớm, Bùi Văn Cường, Nguyễn Hống Hạnh và cs (2018). Thực trạng tuân thủ điều trị tăng huyết áp của người bệnh điều trị ngoại trú tai bệnh viện đa khoa tỉnh Quảng Ninh năm 2017, Tạp chí Khoa học Điêuu dướng, 1(3): 35-42.

7. Thạch Thị Mỹ, Lê Thị Diểm Trinh, Nguyễn La Trí Dũng và CS (2019). Tỷ lệ tuân thủ điêu trị và một số yếu tố liên quan ở bệnh nhân tăng huyết áp người dân tộc Khmer tại BVĐK khu vực Cầu Ngang, tỉnh Trà Vinh, Tạp chí Y học TP. Hồ Chí Minh, 23(2): 224-228.

8. Bộ Y' tế (2012). Hướng dẫn chẩn đoán và điều trị tẳng huyết áp (Ban hành kèm theo Quyết định số 3192/QĐ-BYT ngày 31/8/2010 của Bộ Y tế).

\title{
TÌNH TRANG DINH DƯỡNG Ở' TRẺ 6 THÁNG ĐẾN 5 TUỔI TẠI PHÒNG KHÁM DINH DƯỡNG BỆNH VIỆN NHI TRUNG ƯƠNG
}

\section{Aphanhnee Souliyakane ${ }^{1}$, Nguyễn Thị Yến ${ }^{1}$, Nguyễn Thị Thuý Hồng1, Chu Thị Phương Mai ${ }^{1}$, Lề Hưu Thành ${ }^{2}$}

\section{TÓM TẮT}

Đặt vấn đê: Dinh dưỡng là yếu tố quan trọng trong quá trình phát triển thể chất và tinh thần ở trẻ nhỏ, đặc biệt trẻ dưới 5 tuổi. Mục tiêu: Mô tả tình trang dinh dưỡng ở trẻ từ 6 tháng đến 5 tuổi và một sổ yếu tố liên quan tại Phòng khám Dinh dưỡng Bệnh viện Nhi Trung ương. Đối tượng và phương pháp: Nghiên cứu mô tả cắt ngang 234 trẻ từ 6 tháng đến 5 tuổi đến khám tại Phòng khám Dinh dưỡng Bệnh viện Nhi Trung ương từ tháng 9/2020 đến tháng 6/2021. Trẻ được đánh giá tính trạng dinh dưỡng theo tiêu chuẩn của Tổ chức Y tế Thế giới (WHO) 2006. Kết quả: Tỷ lệ trẻ được bú sữa me trong vòng 1 giờ là $56,0 \%$. Phần lớn trẻ bú mẹ hoàn toàn dưới 6 tháng $(67,1 \%)$. Tỷ lệ trẻ bú mẹ kéo dài trên 18 tháng là $58,8 \%$. Phần lớn trẻ ăn bổ sung đúng thời điểm $(87,0 \%)$; thành phân bữa ăn bổ sung có đủ các nhóm thực phẩm chiếm $67,9 \%$. Đa số trẻ ăn bổ sung đủ số bữa $(77,8 \%)$ nhưng chỉ có $41,9 \%$ trẻ ăn đủ số lượng thức ăn mối bữa. Tỷ lệ suy dinh dưỡng (SDD) thể thấp còi, nhe cân và gây còm lần lượt là $25,6 \%, 22,7 \%$ và $18,4 \%$, thừa cân béo phì chiểm $6,8 \%$. Trẻ có cân

\section{${ }^{1}$ Trường Đại học Y Hà Nội}

²Bênh viện Nội tiết Trung ương

Chịu trách nhiệm chính: Aphanhnee Souliyakane

Email: aphanisouliyakavn@gmail.com

Ngày nhận bài: 2.8.2021

Ngày phản biện khoa học: 24.9.2021

Ngày duyệt bài: 4.10.2021 năng lúc sinh thâp < $2500 \mathrm{~g}$ có nguy cơ suy dinh dưỡng thể nhe cân cao hơn nhóm trẻ có cân nặng lúc sinh bình thướng. Kết luận: Tỷ lệ trẻ SDD ở cả ba thể còn cao, ngoài ra có 1 tỷ lệ không nhỏ trẻ thừa cân béo phì. Cân nặng lúc sinh thấp có liên quan đến tình trạng dinh dướng của trẻ. trẻ em.

Tư khóa: suy dinh dưỡng, tính trạng dinh dưỡng,

\section{SUMMARY}

NUTRITIONAL STATUS IN 6 MONTH TO 5 YEAR OLD CHILDREN AT THE NUTRITION CLINICS OF THE CHILDREN'S NATIONAL HOSPITAL

Background: Nutrition plays an important role in the growth and development of a child, especially under 5 years old. Objectives: This study aimed to assess the nutritional status and associating factors of children aged from 6 months to 5 years old who visited the Nutrition Clinics at the Children's National Hospital. Methods: In this cross-sectional study, the nutirtional history and anthropometrics of 234 children aged from 6 months to 5 years old who visited the Nutrition Clinics at the Children's National Hospital from 9/2020 to 6/2021 were taken and interpreted based on the World Health Organisation (WHO) 2006 growth reference data. Results: $56,0 \%$ of subjects were breast-fed within an hour of life. $67,0 \%$ were fed entirely on breast milk for the first 6 months and $58,8 \%$ for the first 18 months. Complementary feeding was introduced at 6 months of age in $87,0 \%$ and $67,9 \%$ were provided with all food groups. While 
the number of meal per day was sufficient in $77,8 \%$, the meal quantity was adequate in only $41,9 \%$. This study observed that $25,6 \%, 22,7 \%$ and $18,4 \%$ of the children were stunted, underweight, and wasted respectively. The incidence of overweight and obese was $6,8 \%$. Children with low birth weight (under 2500 g) were more likely to have lower weight later on in life. Conclusion: Childhood malnutrition is still a prevalent challenge among children under 5 years old. Birth weight is associated with the nutritional status.

Keywords: malnutrition, nutritional status, children

\section{I. ĐẶT VẤN ĐỀ}

Dinh dưỡng là yếu tố quan trọng trong quá trình phát triến thể chất và tinh thần ở trẻ nhỏ, đặc biệt trẻ dưới 5 tuổi. Theo báo cáo của Tổ chức Nhi đồng Liên hợp quốc (UNICEF) năm 2019 trên toàn cầu có khoảng 144 triệu trẻ dưới 5 tuổi bị suy dinh dưỡng thể thấp còi (chiếm $21,3 \%$ ), 47 triệu trẻ bị suy dinh dưỡng thể gầy còm (chiếm $6,9 \%)^{7}$. Ở Việt Nam, trong những năm qua, tỷ lệ SDD đã có chiều hướng giảm xuống nhưng vẫn còn cao so với thế giới và các nước trong khu vực Suy dinh dương ảnh hưởng đến sự phát triển về thể chất, tinh thần và trí tuệ của trẻ; đồng thời liên quan đến nhiều bệnh lý, đặc biệt là các bệnh nhiếm trùng đường hô hấp và tiêu hoá, làm gia tăng tỉ lệ tử vong ở trẻ. ${ }^{5}$

Hàng năm Bệnh viện Nhi Trung ương đón tiếp một lượng lớn trẻ đến khám vì vấn đề dinh dưỡng, đặc biệt là trẻ từ 6 tháng đến 5 tuổi. Đây là giai đoạn hết sức quan trọng vì ở giai đoạn này, tốc độ tăng trưởng của trẻ nhanh nên nhu cầu dinh dưỡng cao, hơn nữa trẻ chuyển sang ăn thức ăn bổ sung nên rất dễ mắc bệnh về dinh dưỡng. Nếu để trẻ bị SDD trong những năm đầu đời này, nó sẽ ảnh hưởng xấu đến sự phát triển trí tuệ và thể chất của trẻ về sau. Mục tiêu nghiên cứu: Mô tả tình trạng dinh dướng ở trẻ từ 6 tháng đến 5 tuổi và một số yếu tố liên quan tại Phòng khám Dinh dưỡng Bệnh viện Nhi TW.

II. ĐỐI TƯợNG VÀ PHƯƠNG PHÁP NGHIÊN CứU

Đối tượng nghiên cứu. Trẻ từ 6 tháng đênn 5 tuổi đến khám tại Phòng khám Dinh dưỡng Bệnh viện Nhi Trung ương từ tháng 9/2020 đến tháng 6/2021. Bà mẹ của trẻ được chọn hiểu nội dung câu hỏi phỏng vấn và đồng ý tham gia nghiên cứu.

Loại trừ những trẻ mắc các dị tật bẩm sinh, đang mắc các bệnh cấp tính.

Phương pháp nghiên cứu. Nghiên cứu mô tả cắt ngang với cỡ mẫu nghiên cứu thuận tiện. Mỗi trẻ được khám và bà mẹ trả lời bộ câu hỏi phỏng vấn đã được thiết kế trước.
Số liệu được nhập và xử lý bằng phần mềm SPSS 22.0.

\section{Các biến số và chỉ số nghiên cứu, tiêu} chuẩn đánh giá

- Tính tuổi: Tuổi của trẻ được tính bằng cách lấy ngày tháng năm điều tra trừ đi ngày tháng năm sinh của trẻ và phân loại theo WHO, 1995.

+ Trẻ từ 1-29 ngày: 0 tháng tuổi.

+ Trẻ từ 30-59 ngày: 1 tháng tuổi. tuổi.

+Trẻ từ 11 tháng-11 tháng 29 ngày: 11 tháng

- Trẻ được phân loại tình trạng dinh dưỡng theo tiêu chuẩn của WHO 2006. ${ }^{7}$

Dựa vào Z-Score, tính theo công thức:

Kích thước đo được - số trung bình của quần thể tham chiếu

Z-Score = Độ lệch chuẩn của quần thể tham chiếu

\begin{tabular}{|c|c|c|c|}
\hline Z-score & $\mathrm{CC} / \mathrm{T}$ & $\mathrm{CN} / \mathrm{T}$ & $\mathrm{CN} / \mathrm{CC}$ \\
\hline$>3 S D$ & & Béo phì & Béo phì \\
\hline$>2 S D$ & & Thừa cân & Thừa cân \\
\hline $\begin{array}{c}\text {-2SD đến } \\
\text { 2SD }\end{array}$ & $\begin{array}{c}\text { Bình } \\
\text { thường }\end{array}$ & Bình thường & $\begin{array}{c}\text { Bình } \\
\text { thường }\end{array}$ \\
\hline$<-2 S D$ & $\begin{array}{c}\text { Thấp còi } \\
\text { vừa }\end{array}$ & Nhẹ cân vừa & $\begin{array}{c}\text { Gây còm } \\
\text { vừa }\end{array}$ \\
\hline$<-3 S D$ & $\begin{array}{c}\text { Thấp còi } \\
\text { nặng }\end{array}$ & $\begin{array}{c}\text { Nhe cân } \\
\text { nặng }\end{array}$ & $\begin{array}{c}\text { Gầy còm } \\
\text { nặng }\end{array}$ \\
\hline
\end{tabular}

- Bú me hoàn toàn là trẻ chỉ bú mẹ mà không cho ăn/uống bất cứ thức ăn, đồ uống nào khác.

- Số bữa ăn theo lứa tuối.

+ 6 tháng tuổi: 1 bữa bột $200 \mathrm{ml}$. Dưới 1 bát là ít và trên 1 bát là nhiều.

+7-8 tháng: 2 bữa bột $200 \mathrm{ml}$. Dưới 2 bát là ít và trên 2 bát là nhiều.

+ 9-12 tháng: 3 bữa bột $200 \mathrm{ml}$. Dưới 3 bát là ít và trên 3 bát là nhiều

+12-24 tháng: 3 bữa cháo $250 \mathrm{ml}$. Dưới 3 bát là ít và trên 3 bát là nhiều.

- Mỗi bữa ăn cần có ít nhất 5/8 nhóm chất cơ bản và bắt buộc phải có chất béo (bao gồm mõ và dâu).

+ Nhóm 1. Lương thực như gạo, ngô, khoai...

+ Nhóm 2. Nhóm hạt các loại như đậu, đỗ, vừng, lạc...

+ Nhóm 3. Nhóm sữa và các sản phẩm từ sữa.

+ Nhóm 4. Nhóm thịt các loại, cá và hải sản.

+ Nhóm 5. Nhóm trứng và các sản phẩm của trứng.

+ Nhóm 6. Nhóm củ quả màu vàng, da cam, màu đỏ hoặc rau tươi có màu xanh thẩm.

+ Nhóm 7. Nhóm rau củ quả khác như su hào, củ cải cung cấp vitamin, chất khoáng và chất xơ. + Nhóm 8. Nhóm dâu ăn, mõ các loại. 


\section{KẾT QUẢ NGHIÊN CỨU}

Nghiên cứu tiến hành trên 234 trẻ có tuổi trung bình $27,9 \pm 17,3$ tháng và tỉ lệ trẻ nam/nữ là $1,4: 1$.

Bảng 1. Đặc điểm nuôi con bằng sữa mẹ

\begin{tabular}{|c|c|c|c|}
\hline \multicolumn{2}{|c|}{ Thực hành } & Tần số & Tỉ \%) \\
\hline $\begin{array}{c}\text { Thời điểm } \\
\text { bú mè sau } \\
\text { sinh }\end{array}$ & $\begin{array}{c}\text { Trong vòng } \\
1 \text { giờ }\end{array}$ & 131 & 56,0 \\
\cline { 2 - 4 } & Sau 1 giờ & 103 & 44,0 \\
\hline $\begin{array}{c}\text { Thời gian } \\
\text { bú me } \\
\text { hoàn toàn }\end{array}$ & \begin{tabular}{c}
$<6$ tháng \\
\cline { 2 - 4 } đtháng \\
đâuu
\end{tabular} & 157 & 67,1 \\
\hline
\end{tabular}

Nhận xét: Tỉ lệ trẻ được bú sữa mẹ trong vòng 1 giờ là $56,0 \%$. Phần lớn trẻ bú mẹ hoàn toàn dưới 6 tháng.

Bảng 2. Đặc điểm cho ăn bổ sung $(n=207)$

\begin{tabular}{|c|c|c|c|}
\hline \multirow{2}{*}{ Đặc điểm } & $\begin{array}{c}\text { Tân số } \\
\text { (n) }\end{array}$ & $\begin{array}{c}\text { Tỉ lệ } \\
\text { \% }\end{array}$ \\
\hline \multirow{2}{*}{$\begin{array}{c}\text { Thời điểm trẻ bắt đầu } \\
\text { ăn bố sung }\end{array}$} & Đúng & 180 & 87,0 \\
\cline { 2 - 4 } & Sớm & 14 & 6,8 \\
\cline { 2 - 4 } & Muộn & 13 & 6,3 \\
\hline Thức ăn đầu tiên khi & Bột nấu & 203 & 86,8 \\
\cline { 2 - 4 } ăn bổ sung & Khác & 31 & 13,2 \\
\hline Thành phần các nhóm & Đủ & 159 & 67,9 \\
\cline { 2 - 4 } thực phẩm/ ĂBS & Không đủ & 75 & 32,1 \\
\hline Số lượng/bữa & Đủ & 98 & 41,9 \\
\cline { 2 - 4 } & Thiếu & 136 & 58,1 \\
\hline
\end{tabular}

\begin{tabular}{|c|c|c|c|}
\hline Số bữa ăn theo & Đúng & 182 & 77,8 \\
\cline { 2 - 4 } khuyến nghị & Sai & 52 & 22.2 \\
\hline
\end{tabular}

\section{Nhân xét:}

- Phần lớn trẻ trong nghiên cứu được ăn bổ sung đúng thời điểm $(87,0 \%)$.

- Thức ăn đâu tiên chủ yếu là bột nấu (86,8\%).

- Khoảng $1 / 3$ số trẻ ăn bổ sung không đủ thành phần các nhóm thực phẩm. bữa.

- Chỉ 41,9\% trẻ ăn đủ lượng thức ăn cho mỗi

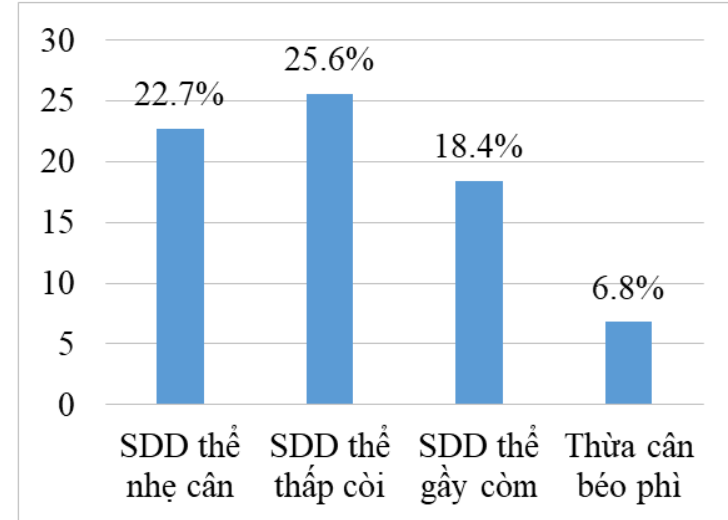

Biểu đồ 1. Tình trạng dỉnh dưỡng của trẻ trong nghiên cứu $(n=234)$

Nhận xét: Tỷ lệ trẻ suy dinh dưỡng thể thấp còi chiếm tỉ lệ cao nhất $(25,6 \%)$, bên cạnh đó tỷ lệ trẻ thừa cân béo phì chiếm $6,8 \%$.

Bảng 3. Liên quan giữa một số yếu tố với TTDD theo chỉ tiêu CN/T

\begin{tabular}{|c|c|c|c|c|c|}
\hline \multirow{2}{*}{\multicolumn{2}{|c|}{ Yếu tố liên quan }} & \multicolumn{2}{|c|}{ Cân nặng/tuối } & \multirow{2}{*}{$\begin{array}{c}\text { OR } \\
(95 \% \mathrm{CI})\end{array}$} & \multirow{2}{*}{$\mathbf{p}$} \\
\hline & & \multirow{2}{*}{$\frac{\text { SDD }}{23(24,5)}$} & \multirow{2}{*}{$\frac{\text { Không SDD }}{71(75,5)}$} & & \\
\hline \multirow{3}{*}{$\begin{array}{c}\text { Nghề } \\
\text { nghiệp } \\
\text { của mẹ }\end{array}$} & Làm ruộng & & & & \multirow{3}{*}{0,18} \\
\hline & Buôn bán, nội trợ & $15(23,4)$ & $49(76,6)$ & & \\
\hline & Cán bộ, CNVC & $15(19,7)$ & $61(80,3)$ & & \\
\hline \multirow{4}{*}{$\begin{array}{l}\text { TĐHV của } \\
\text { mẹ }\end{array}$} & Tiểu học & $5(17,2)$ & $24(82,8)$ & & \multirow{4}{*}{1,0} \\
\hline & Trung học cơ sở & $7(26,9)$ & $19(73,1)$ & & \\
\hline & TH phổ thông & $19(26,8)$ & $52(73,2)$ & & \\
\hline & Cao đằng, đại học & $22(20,4)$ & $86(79,6)$ & & \\
\hline \multirow{2}{*}{ Địa dư } & Thành thị & $13(18,6)$ & $57(81,4)$ & \multirow{2}{*}{$\begin{array}{c}1,2 \\
(0,8-4,1)\end{array}$} & \multirow{2}{*}{0,31} \\
\hline & Nông thôn, miền núi & $40(24,4)$ & $124(75,6)$ & & \\
\hline \multirow{2}{*}{$\begin{array}{l}\text { Cân năng } \\
\text { lúc sinh }\end{array}$} & $<2500 \mathrm{~g}$ & $19(31,1)$ & $42(68,9)$ & \multirow{2}{*}{$\begin{array}{c}0,5 \\
(0,1-0,8)\end{array}$} & \multirow{2}{*}{0,03} \\
\hline & $\geq 2500 \mathrm{~g}$ & $34(19,7)$ & $139(80,3)$ & & \\
\hline \multirow{2}{*}{$\begin{array}{c}\text { Thời gian } \\
\text { BSMHT }\end{array}$} & $<6$ tháng & $36(22,9)$ & $121(77,1)$ & \multirow{2}{*}{$\begin{array}{c}1,0 \\
(0,4-12,6)\end{array}$} & \multirow{2}{*}{0,91} \\
\hline & $\geq 6$ tháng & $17(22,1)$ & $60(77,9)$ & & \\
\hline \multirow{2}{*}{$\begin{array}{c}\text { Thời điể̉m } \\
\text { ăn bổ } \\
\text { sung }\end{array}$} & $<6$ tháng & $2(14,3)$ & $12(85,7)$ & \multirow{2}{*}{$\begin{array}{c}1,8 \\
(0,7-6,8)\end{array}$} & \multirow[b]{2}{*}{0,22} \\
\hline & $\geq 6$ tháng & $51(23,2)$ & $169(76,8)$ & & \\
\hline \multirow{2}{*}{$\begin{array}{c}\text { Thời điểm } \\
\text { cai sữa }\end{array}$} & $<18$ tháng & $17(27,9)$ & $44(72,1)$ & \multirow{2}{*}{$\begin{array}{c}1,0 \\
(0,3-6,1)\end{array}$} & \multirow{2}{*}{0,87} \\
\hline & $\geq 18$ tháng & $24(27,6)$ & $63(72,4)$ & & \\
\hline
\end{tabular}

Nhận xét: Nhóm trẻ có cân nặng lúc sinh bình thường có nguy cơ suy dinh dưỡng thể nhẹ cân thấp hớn so với nhóm trẻ có cân nặng lúc sinh bình thường với $p<0,05$. 


\section{BÀN LUÂN}

Theo khuyến cáo của WHO, UNICEF các bà mẹ nên cho con bú trong vòng một giờ đầu sau sinh và bú càng sớm càng tốt. ${ }^{7}$ Trong nghiên cứu của chúng tôi chỉ có $56 \%$ trẻ được bú mẹ trong vòng 1 giờ sau khi sinh. Có nhiều lý do khiến bà mẹ không cho con bú sớm như trẻ bị bệnh, mẹ đẻ mổ, đau sau sinh...

Chiến lược toàn cầu về nuôi dưỡng trẻ sơ sinh và trẻ nhỏ của WHO/UNICEF đã đưa ra bằng chứng khoa học về tính ưu việt của thực hành nuôi con bằng sữa mẹ và khuyến nghị trẻ cần được nuôi dưỡng hoàn toàn bằng sữa me trong 6 tháng đầu của cuộc đời. Trong nghiên cứu của chúng tôi phần lớn trẻ không bú mẹ hoàn toàn trong 6 tháng đầu $(67,1 \%)$. Nguyên nhân chính được cho là do các bà me sợ con đói và me phải đi làm, mẹ nghĩ ăn thêm tốt hơn...Đây là những quan điểm sai lầm phổ biến trong thực hành dinh dưỡng ở trẻ, cần thêm những chương trình truyền thông giáo dục nhằm tăng cường nhận thức của người dân và các bà mẹ về vấn đề này.

Cho trẻ ăn bổ sung sớm không có lợi cho sức khỏe của trẻ vì cho trẻ ăn bổ sung sớm khiến trẻ bú ít đi, sữa được sản sinh ra ít hơn và trẻ mất nguồn dinh dưỡng quý giá từ sữa mẹ. Theo khuyến cáo của Viện Dinh dưỡng Quốc gia, từ 6 tháng tuổi trở lên ngoài sữa me trẻ cần được ăn bổ sung các loại thực phẩm khác ${ }^{4}$. Trong nghiên cứu của chúng tôi, phần lớn trẻ ăn bổ sung đúng thời điểm $(87,0 \%)$; chỉ $67,9 \%$ trẻ ăn bổ sung đủ thành phần các nhóm thực phẩm. Nghiên cứu của tác giả Chu Thị Phương Mai cho thấy nhóm trẻ ăn không đủ các nhóm thực phẩm cơ bản có nguy cơ suy dinh dưỡng cao gấp 2,1 lần so với nhóm ăn đủ các nhóm thực phẩm. ${ }^{2}$ Đa số trẻ ăn bổ sung đủ số bữa $(77,8 \%)$ nhưng chỉ có $41,9 \%$ trẻ ăn đủ số lượng thức ăn cho mổi bữa.

Theo báo cáo của UNICEF/WHO, tỷ lệ suy dinh dưỡng có xu hướng giảm theo thời gian do sự phát triển của kinh tế xã hội, điều kiện chăm sóc y tế và chế độ dinh dưỡng được cải thiện. So với năm 2000, tỷ lệ suy dinh dưỡng thể thấp còi năm 2019 đã giảm từ 32,4\% xuống còn $21,3 \%$. Tuy nhiên, tỉ lệ thừa cân béo phì lại tăng lên từ $4,9 \%$ lên $5,6 \% .{ }^{4}$ Kết quả nghiên cứu của chúng tôi cho thấy tỷ lệ suy dưỡng thể thấp còi, nhe cân và gầy còm lần lượt là $25,6 \%, 22,7 \%$ và $18,4 \%$; bên cạnh đó tỷ lệ trẻ thừa cân béo phì cũng là $6,8 \%$. Kết quả này cho thây tỷ lệ SDD trong nghiên cứu cao hơn đáng kể so với các nghiên cứu trong cộng đồng; theo thống kê của Viện Dinh dưỡng Quốc gia tỳ lệ SDD của cả nước năm 2017 với thể nhẹ cân, thấp còi và gầy còm lần lượt là $13,4 \%, 23,8 \%$ và 5,8\%.

Sự chênh lệch về tỷ lệ các thể SDD trong kết quả nghiên cứu của chúng tôi so với các nghiên cứu khác có thể được lý giải là do chúng tôi tiến hành nghiên cứu tại Phòng khám Dinh dưỡng, nơi các bênh nhi đển khám vì đều có các vấn đề về dinh dưỡng. Hơn nữa, đối tương nghiên cứu của chúng tôi ở độ tuổi từ 6 tháng đến 5 tuổi. Đây là nhóm có nguy cơ cao bị SDD bởi giai đoạn này cơ thể trẻ lại phát triển nhanh về thể chẩt, vận động và tinh thần do đó tăng nhu cầu năng lượng và các vi chất. Hơn nữa, hê miễn dịch của trẻ chưa hoàn thiện, cơ thể trẻ liên tục tiếp xúc với những yếu tố môi trường trong khi kháng thể thụ động từ sữa me giảm, làm cho trẻ dễ mắc bệnh và rơi vào vòng xoắn bệnh lý nhiễm trùng và SDD Do vậy, cần tập trung can thiệp tích cực vào nhóm tuổi này.

SDD thấp còi được coi là chỉ tiêu phản ánh sự phát triển của xã hội, phản ánh tình trạng thiếu dinh dưỡng kéo dài hoặc SDD trong quá khứ làm cho trẻ bị còi cọc và là chỉ số đánh giá hậu quả của sự đói nghèo. Trong nghiên cứu của chúng tôi tỷ lệ SDD thể thấp còi chiếm tỉ lệ 25,6\%. Hiện nay, SDD thể thấp còi đang là vấn để phổ biển tai tất cả các vùng sinh thái trên cả nước. Cải thiện tình trạng SDD thể thấp còi sẽ giúp nâng cao tầm vóc, thể lực và trí tuệ người Việt Nam.

Trong nghiên cứu của chúng tôi, nhóm trẻ có cân nặng khi sinh dưới 2500 gam có nguy cơ SDD cao gấp 2 lần so với nhóm trẻ có cân nặng khi sinh từ 2500 gam trở lên. Trẻ có cân nặng khi sinh thấp sẽ là yếu tố nguy cơ tử vong, là nguyên nhân quan trọng dẫn đến sự kém phát triển cả về thể chất tinh thần và vận động không những trong thời kỳ chu sinh mà còn gây SDD cho trẻ sau này. Điều này đã được nêu lên trong nghiên cứu của các tác giả nước ngoài như Kátia và $\mathrm{CS}^{6}$ và các nghiên cứu trong nước của Chu Thị Phương Mai, ${ }^{2}$ Phạm Văn Hoan. ${ }^{3}$

Các yếu tố khác về nhân khẩu học của bà me gồm nghề nghiệp, trình độ văn hóa, địa dư hay những đặc điểm nuôi dưỡng trẻ như thời gian trẻ được bú me hoàn toàn, thời điểm ăn bổ sung, thời gian cai sữa không có liên quan đến tỷ lệ SDD thể nhe cân ở trẻ. Một số tác giả cho rằng những bà mẹ có nghề nghiệp là cán bộ có nhiều thời gian hơn để chăm sóc trẻ và có kiển thức tốt hơn trong chăm sóc dinh dưỡng cho trẻ. Tuy nhiên, trong những năm gần đây chúng tôi nhận thấy nhiều người có cán bộ viên chức có thời gian làm việc tại cơ quan nhiều hơn, trong đó những bà mẹ làm ruộng lại có nhiêu thời gian chăm sóc trẻ và cho trẻ bú mẹ. Đây có thể là 
nguyên nhân dân đế sự khác biệt của nghiên cứu của chúng tôi so với nghiên cứu của những tác giả khác. Trình độ học vấn của mẹ thể hiện qua cách nuôi dưỡng và chăm sóc trẻ. Bà me có học vấn cao sẽ dễ dàng trong việc tiếp thu các thông tin về cách nuôi dưỡng con cũng như cách xử trí đúng khi con bị bệnh. Tuy nhiên, nhiều trường hợp người chăm sóc trực tiếp cho trẻ không phải bà mẹ, điều này sẽ ảnh hưởng đến thực hành nuôi dưỡng trẻ.

Nhiều nghiên cứu đã cho thây liên quan giữa thực hành nuôi con bằng sữa me như thời gian bú mẹ hoàn toàn, thời gian cai sữa với tình trạng dinh dưỡng ở trè. Tuy nhiên, trong nghiên cứu của chúng tôi cõ̃ mẫu có thể chưa đủ lớn, ngoài ra các đối tượng trong nghiên cứu của đều có các vấn đề về dinh dưỡng kèm theo như bệnh lý, hoặc các sai lầm nuôi dưỡng khác... Vì vậy, cần có những nghiên cứu lớn và sâu hơn để đánh giá ảnh hưởng của từng yếu tố đến tính trạng dinh dưỡng của trẻ.

\section{KẾT LUẬN}

Tỷ lệ trẻ SDD ở cả ba thể còn cao, ngoài ra có 1 tỳ lệ không nhỏ trẻ thừa cân béo phì. Một số yếu tố có liên quan đến tình trạng dinh dưỡng của trẻ, trong đó tỷ lệ SDD thể nhẹe cân cao hơn ở nhóm trẻ cân nặng lúc sinh thấp so với nhóm trẻ có cân nặng khi sinh bình thường.

TÀI LIỆ THAM KHẢO

1. Viện Dinh Dưỡng (2006), "Tình trạng dinh dưỡng trẻ em và bà mẹ năm 2005", Nhà xuất bản Y Học.

2. Chư Thị Phương Mai, Nguyễn Thị Viêt Hà (2014). Đánh giá tình trạng suy dinh dướng và một sô yếu tố ảnh hưởng đển dinh dưỡng của trẻ từ 6-24 tháng tuổi tại Phòng khám Dinh dưỡng, Bệnh viện Nhi Trung ương. Tạp chí Nhi khoa.

3. Phạm Văn Hoan, Nguyến Lan Phương và cộng sự (2009). Thức trang suy dinh dưỡng trẻ em dưới 5 tuổi, kiến thức thựcc hành nuôi con của bà me ở Xã Phù Linh, Sóc Sớn, Hà Nội 2008. Tạp chí DD̉\&TP, 5 (2).

4. Organization WH. UNICEF/WHO/The World Bank Group joint child malnutrition estimates: levels and trends in child malnutrition: key findings of the 2020 edition. 2020.

5. Brabin BJ, Premji Z, Verhoeff F. An analysis of anemia and child mortality. The Journal of nutrition. 2001;131(2):636S-648S.

6. Kátia B.R.S, Jullyana F.R.A, and all (2010). Association between malnutrition in children living in favelas, maternal nutritional status, and environmental factors. Journal de Pediatria, 86(3), 215-220.

7. WHO, UNICEF, USAID, AED, UCDAVIS and IFPRI (2008), Indicators for assessing infant and young child feeding practices, Consensus meeting, Washington, DC, pp. 5-11.

\section{KHẢO SÁT MỐI LIÊN QUAN GIỮA GENOTYPE VÀ TÌNH TRẠNG KHÁNG CLARITHROMYCIN CỦA HELICOBACTER PYLORI Ở BỆHH NHÂN VIÊM LOÉT DẠ DÀY TÁ TRÀNG}

Đào Thanh ${ }^{1}$, Trần Đỗ Hùng ${ }^{2}$, Trần Thị Như L $\hat{e}^{2}$, Nguyễn Văn Lâm², Tạ Văn Trầm ${ }^{4}$, Nguyễn Ngọc Hằng ${ }^{4}$, Liêu Trường Khánh ${ }^{5}$, Lê Thị Gái ${ }^{2}$, Bùi Ngọc Niệm², Âu Xuân Sâm², Huỳnh Minh Trúc ${ }^{3}$

\section{TÓM TẮT}

Đắt vấn đê: Tình trang kháng clarithromycin đang gia tăng trên toàn thế giới và là nguyên nhân phổ biến nhất dân đến thất bai trong điều trị Helicobacter pylori. Mục tiêu nghiền cứu: xác định tỷ lệ kháng clarithromycin của Helicobacter pylori ở bệnh nhân

\footnotetext{
${ }^{1}$ Trung tâm Y tế huyện Thới Lai

${ }^{2}$ Trường Đại học Y Dược Cần Thơ

${ }^{3}$ Trung tâm Kiểm soát bệnh tật Cần Thơ

${ }^{4}$ Bệnh viện Đa Khoa Trung Tầm Tiền Giang

5Bệnh viện Đa Khoa Trung Ương Cần Thơ

Chịu trách nhiệm chính: Đào Thanh

Email: daothanhtl1980@gmail.com

Ngày nhận bài: 3.8.2021

Ngày phản biện khoa học: 29.9.2021

Ngày duyệt bài: 5.10 .2021
}

viêm, loét dày - tá tràng và mối liên quan giữa genotype và tình trang kháng clarithromycin của Helicobacter pylori. Đối tượng và phương pháp nghiên cứu: Nghiên cứu cắt ngang được thực hiện trên các bệnh nhân viêm loét dạ dày tá tràng tại tỉnh Tiền Giang 5/2020 đến tháng 5/2021. Những bệnh nhân được phỏng vấn, khám lâm sàng, thu thập mẫu niêm mạc dạ dày tá tràng. Bệnh nhân được xác định nhiễm Helicobacter pylori khi có ít nhất 2 xét nghiệm nhuộm gram, urease test dương hoặc xét nghiệm nuôi cấy định danh dương tính với Helicobacter pylori. Helicobacter pylori được xác định kháng clarithromycin bằng kỹ thuật E-test và xác định genotype bằng kỹ thuật Realtime-PCR. Kết quả: Tỷ lệ đề kháng clarithromycin của vi khuẩn Helicobacter pylori trên bệnh nhân tham gia nghiên cứu là 77,3\%. Nhóm bệnh nhân nhiếm chủng Helicobacter pylori mang genotype $\operatorname{cag} \mathrm{A}(+)$ có tỷ lệ đề kháng kháng sinh cao hơn nhóm bệnh nhân nhiễm chủng Helicobacter pylori mang 